\title{
FRACTURE AND ITS ROLE IN DETERMINING ICE FORCES ON OFFSHORE STRUCTURES
}

A. C. Palmer,

(R. J. Brown and Associates, P.O. Box 345, 2280 AH Rijswijk (ZH), The Netherlands)

D. J. Goodman,

(British Petroleum Development (Overseas), Britannic House, Moor Lane, London EC2Y 9BU, England)

M. F. Ashby,

(Department of Engineering, University of Cambridge, Cambridge CB2 1PZ, England)

A. G. Evans,

(Department of Materials Science, University of California, Berkeley, California 94720, U.S.A.)

\section{J.W. Hutchinson}

(Division of Applied Sciences, Harvard University, Cambridge, Massachusetts 02139, U.S.A.)

and A. R. S. Ponter

(Engineering Department, University of Leicester, Leicester OL1 7RH, England)

\section{ABSTRACT}

One of the most conspicuous phenomena in the Arctic is the fracture of sea ice. It is scarcely possible to travel far without seeing a variety of fracture forms, produced both by natural processes and by human activity.

At strain-rates below about $10^{-4} \mathrm{~s}^{-1}$, deformation is dominated by creep, but at higher strainrates fracture is much more important. One of the reasons for this is the very low fracture toughness of ice. The movements of ice in contact with offshore structures often induce strain-rates well beyond the level at which fracture begins, and so offshore structures will often operate in the fracture regime, and it is fracture processes which will determine the design loads. We consider the different modes of repeated fracture that will occur, and classify them into distinct mechanisms of crushing, spalling, and radial and circumferential cracking. Experimenta and field observations are plotted on a deformation mode map. A theoretical treatment of radial cracking confirms that very low loads can propagate cracks to long distances; these loads are small by comparison with those calculated from theoretical models that treat ice as a plastically-deforming continuum.

\section{INTRODUCTION}

An engineer who studies the research literature on ice forces finds analyses dominated by theoretical models which treat ice as a material that deforms continuously. Most of the models apply plasticity theory (generally concerned with a material which can deform indefinitely at a certain stress 1evel), and some are based on creep and elasticity.

An observer in the Arctic sees a picture which is qualitatively different. Everywhere he looks, he sees broken ice, sometimes from horizon to horizon. The broken fragments are separated by cracks, and superficially at least they appear to have deformed relatively little, though there may be signs of continuous deformation by creep and flexural buckling, particularly in highly-stressed areas. This observation suggests that any complete analysis of ice forces on offshore structures has to take account of discontinuous fracture phenomena.

It is hardly surprising that fracture should be important. Common experience tells us that ice breaks easily, and measurements show it to have a fracture toughness of the order of $115 \mathrm{kN} \mathrm{m}^{-3 / 2}$ (Goodman 1980), which is less than that of glass and one-thousandth that of structural steel. This fact is reflected in measurements of stress-strain-time relations.

Figure 1, based on unpublished work by Ashby and Cooksley, shows schematically the relationship between minimum strain-rate and stress for pure ice in uniaxial tension and compression at $-10^{\circ} \mathrm{C}$. At $10 \mathrm{w}$ strain-rates, ice creeps continuously, and strainrate and stress are related by a power law (Glen's law), and behaviour in tension and compression is almost identical. At strain-rates above $10^{-5} \mathrm{~s}^{-1}$ in tension and $10^{-4} \mathrm{~s}^{-1}$ in compression, fracture processes take over and become much more important than creep, though creep may still be significant at a microstructural level. In tension, fracture occurs at a stress between 1 and $2 \mathrm{MN} \mathrm{m}^{-2}$, depending on grain 


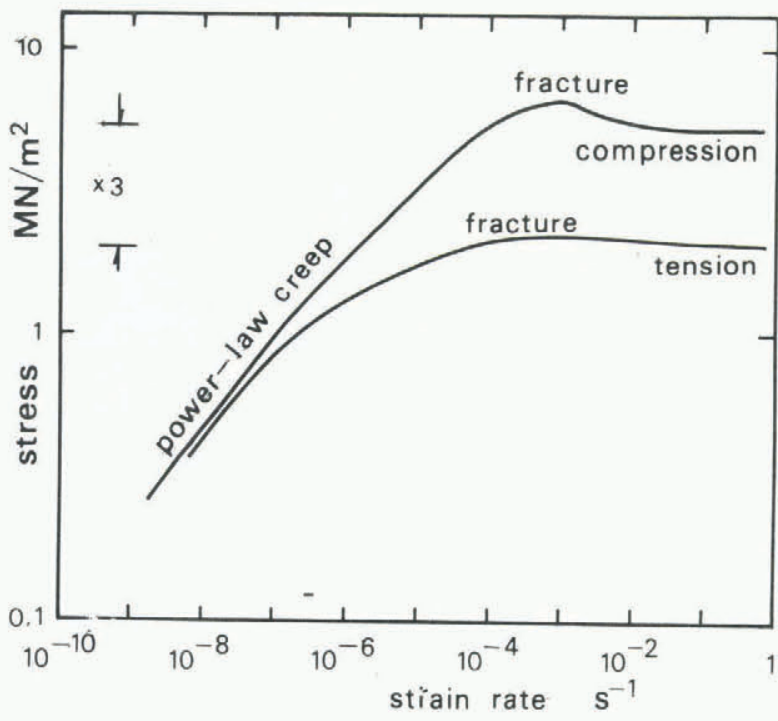

Fig.1. Relation between minimum strain-rate and stress for pure ice in uniaxial compression and tension at $-10^{\circ} \mathrm{C}$.

size. This is probably due to the unstable propagation of pre-existing microcracks or of cracks nucleated by creep deformation, on the same scale as the grain size. In compression, microcracks probably do not begin to propagate until a higher stress level is reached, and fracture follows the linking up of these distributed inicrocracks. A difference between tensile and compressive strengths is characteristic of brittle materials, though a factor of three between them is much smaller than in concrete and rocks.

The central role of fracture is confirmed by comparison of a number of situations in which ice deforms. They are listed in Table I. Each is identified by creep (in which deformation is continuous and the ice does not break up) or by fracture (in which markedly discontinuous deformation breaks the ice into distinct fragments). The classification is based on a broad macroscopic interpretation, and it has to be kept in mind that what appears as fracture on a large scale may also include intense creep deformation at crack tips. Each deformation has a characteristic velocity IJ and length L (defined as the distance over which the relative velocity is $U$ ); $U / L$ has the dimensions of strain-rate if the deformation is continuous.

The comparison in Table I shows that creep dominates in slow natural processes, and fracture dominates when velocities are higher. It is consistent with the stress strain-rate relation, where fracture takes
over from creep when strain-rates exceed $10^{-4} \mathrm{~s}^{-1}$.
An offshore structure could have a diameter of at least $100 \mathrm{~m}$, perhaps much more. The velocity of drifting ice is in the range 0 to $1 \mathrm{~m} \mathrm{~s}^{-1}$. It follows that the velocity/diameter ratio ranges from 0 to $10^{-2} \mathrm{~s}^{-1}$. If this is the ratio that determines the deformation mode, and if the critical value is $10^{-4} \mathrm{~s}^{-1}$ (which is of the right order of magnitude for a situation dominated by compression but without strong triaxial constraint), then creep will be the dominant mechanism if the velocity is less than $10^{-2} \mathrm{~m} \mathrm{~s}^{-1}\left(1 \mathrm{~km} \mathrm{~d}^{-1}\right)$, and fracture will be the dominant mechanism if the velocity is greater than that. However, observations indicate that the transition to fracture-dominated mechanisms occurs at a much smaller ice velocity: this may be because the length scale should be the ice thickness, or the characteristic length for a floating ice cover, rather than the structure diameter.

\section{DEFORMATION MODES}

The word "fracture" covers more than one kind of behaviour. Many authors have classified their observations of fracture in different ways (e.g. Schwarz and Hirayama 1973, Croasdale 1975, Kry 1982). Figure 2 illustrates one tentative classification of fracture modes close to the contact between ice and a structure. Crushing fracture (Fig.2(a)) involves the growth of cracks in different directions, with no obvious preferred orientation, through a zone whose dimensions are of the same order as the contact breadth and less than the ice thickness. The fragments are relatively smal1, and their length, width and thickness are of the same order. Indentation spalling (Fig.2(b)) occurs when horizontal cracks run roughly parallel to the plane of the ice, until they run out on the upper or lower surface. The spall fragments are semicircular: their thickness is less than that of the ice, and their radius much larger. Radial cracking (Fig.2(c)) is the growth of vertical cracks, directed radially from the contact region and running through the whole thickness. In a large ice cover radial cracks alone do not separate the ice into fragments, but they are often accompanied by circumferential cracks (Fig.2(d)) so that the fragments are triangular and trapezoidal. Modes are often mixed; in particular, it of ten happens that the contact region undergoes local crushing while radial cracks develop further away.

All four modes are observed in the field and in the laboratory, but the facts that decide which of thein will occur are not fully understood. When a uniform ice cover moves against a cylindrical structure, the principal governing factors are the ice velocity $U$, the structure diameter $D$, the ice thickness $t$, and the breadth $L$ of the contact between the structure and the ice ( $D$ and $L$ are defined in Fiqure $2)$. Ice material properties such as temperature,

TABLE I. DEFORMATION MODF.S

\begin{tabular}{|c|c|c|c|c|}
\hline & $\begin{array}{l}\text { Velocity } \\
\text { U }\left(m \mathrm{~s}^{-1}\right)\end{array}$ & $\begin{array}{l}\text { Length } \\
\mathrm{L}(\mathrm{m})\end{array}$ & $\begin{array}{l}U / L \\
s^{-1}\end{array}$ & $\begin{array}{l}\text { Mode of } \\
\text { deformation }\end{array}$ \\
\hline Antarctic ice cap & $3 \times 10^{-8}$ & $10^{3}$ (depth) & $3 \times 10^{-11}$ & creep \\
\hline Alpine valley glacier & $3 \times 10^{-7}$ & $10^{2}$ (depth) & $3 \times 10^{-9}$ & creep \\
\hline surging glacier & $3 \times 10^{-6}$ & $10^{2}$ (depth) & $3 \times 10^{-8}$ & fracture/creep \\
\hline iceberg calving & $10^{-3}$ & $10^{2}$ (thickness) & $10^{-5}$ & creep/fracture \\
\hline laboratory compression test & $10-5$ & $10^{-1}$ (length) & $10^{-4}$ & creep/fracture \\
\hline laboratory indentation test & $10^{-5}$ & $\begin{array}{c}10^{-3} \text { (indenter } \\
\text { radius) }\end{array}$ & $10^{-2}$ & creep/fracture \\
\hline Arctic gravel production island & 1 & $10^{2}$ (diameter) & $10^{-2}$ & \\
\hline rubble field & 1 & $10^{2}$ (width) & $10^{-2}$ & fracture \\
\hline icebreaker & 2 & 20 (beam) & $10^{-1}$ & fracture/bending \\
\hline monopod offshore structure & 2 & (diameter) & $10^{-1}$ & \\
\hline bridge pier & 2 & 2 (diameter) & 1 & fracture \\
\hline ice ditcher & 1 & $10^{-3}$ (cut) & $10^{3}$ & fracture \\
\hline
\end{tabular}



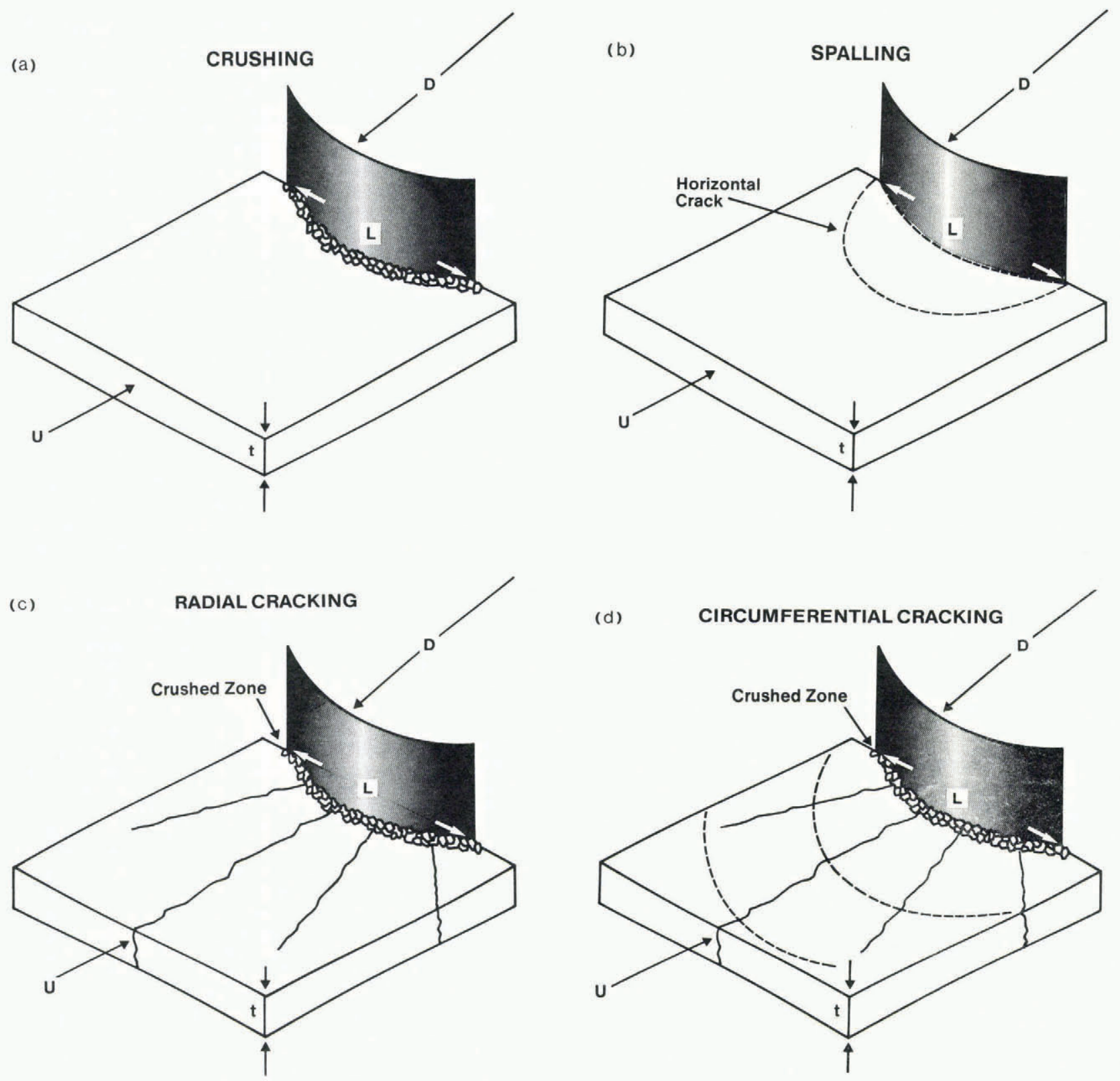

Fig.2(a), (b), (c), (d). Fracture modes.

salinity, grain size, grain orientation, and through thickness variations are also important. It is conjectured that the mode of deformation depends on the ratios $U / D$ and $L / t$. $U / D$ is the deformation rate identified earlier, and $L / t$ determines the type of stress field that can exist close to the contact, since small L/t corresponds to plane strain and large $\mathrm{L} / \mathrm{t}$ to $\mathrm{plane}$ stress.

Figure 3(a) plots observations of deformation modes on a diagram with axes $U / D$ and $L / t$ (with logarithmic scales). Many of the data come from tests with $f l$ at indenters, when $L$ and $D$ are equal. Although the data are not entirely consistent, a pattern does emerge. Figure $3(b)$ is a tentative deformation mode map intended ultimately to be used in the same way as diagrams delineating the regimes of applicability of different wave theories (Sarpkaya and Isaacson 1981), or regime naps in two-phase flow theory. It needs to be emphasized that this map is highly tentative and that it is based on 1 imited data from observations on a small scale. It needs to be completed and corrected as observations on fullscale offshore structures and artificial islands become available.

\section{FRACTURE ANALYSIS}

A long-tern objective is to find a reliable way of predicting ice forces on structures needed for offshore petroleuri production. The design maximur force on a structure will sometimes be limited by the maximun driving forces exerted on the ice by the environment (Croasdale and Marcellus 1932), but more often it will be limited by the strength of the ice itself. The maximum load must therefore depend on the deformation mode. One night compare the degree of variability between modes with that seen in civil engineering fluid mechanics, where flow is sometimes laminar, sometimes turbulent, sometimes dominated by waves, cavities and wakes, and sometimes influenced by multiphase phenomena such as cavitation and sediment transport.

Models based on plasticity theory have been widely applied (Ralston 1978), but are open to critic- 


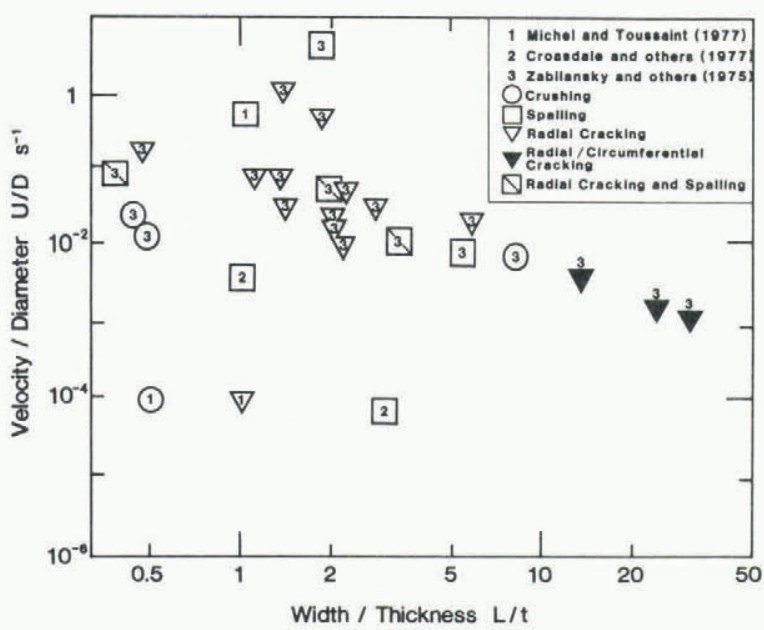

Fig.3(a). Observations of fracture modes as a function of U/D (ice velocity/structure diameter) and $\mathrm{L} / \mathrm{t}$ (contact width/ice thickness).

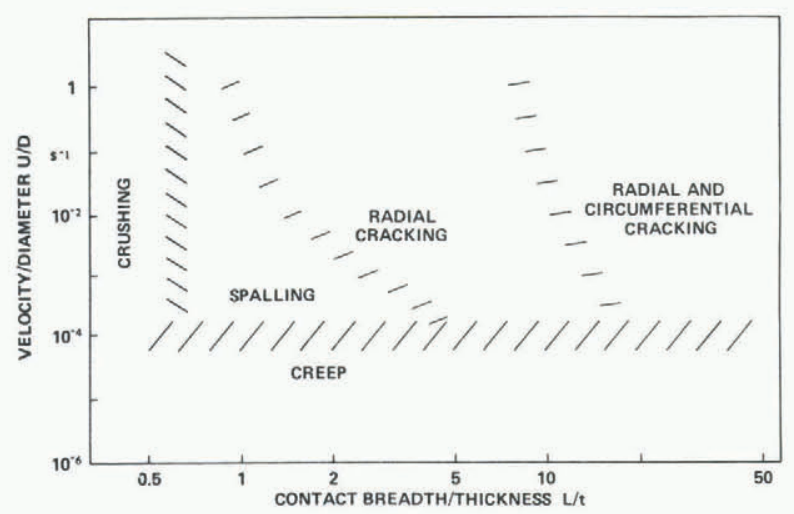

Fig.3(b). Deformation mode map.

ism as inadequate models of ice. The creep regime is discussed in another paper (Ponter and others in preparation*) using a method developed for the analysis of creep deformation in complex stress states. In the fracture regime, complete theories of all the different modes are not yet available. Here we outline a simple theory of radial cracking, intended to lead towards more refined theories and to generate order-of-magnitude estimates of cracking forces. Indentation spalling is discussed elsewhere (Evans and others in preparation [no title available]).

Fracture can begin at extremely low force levels. Imagine a uniform ice cover with a plane vertical side moving into contact with a fixed rigid circular cylindrical structure, fast enough for the ice to respond elastically to stress. The maximum contact pressure $\mathrm{p}_{m}$ is related to the force $P$ between the structure and the ice cover by Hertzian contact theory, and is

$$
\mathrm{p}_{\mathrm{m}}=\left[\frac{2 P E}{\pi D t\left(1-\nu^{2}\right)}\right]^{1 / 2},
$$

where $D$ is the structure diameter, $t$ the ice thickness, $E$ Young's modulus, and $\nu$ Poisson's ratio. The contact breadth is $2 \mathrm{Dpm} / \mathrm{E}$, and so conditions close to

* Ponter A R S, Palmer A C, Goodman D J, Ashby M F, Evans $A G$, Hutchinson $J W$. The force exerted by a moving ice sheet on an offshore structure: I. The creep mode. the contact generally correspond to plane strain through most of the thickness; in plane stress, the factor $1-v^{2}$ is absent. In the contact region, the principal stresses close to the upper and lower surfaces of the ice cover will be $p_{m}$ (in a roughly radial principal direction), of the order of $p$. (circumferentially) and close to zero (vertically) (Frederking and Gold 1972). It follows that if the ice crushes in uniaxial compression at a stress $\sigma_{c}$ crushing can be expected when $p_{i n} \sim \sigma_{\mathrm{C}}$, that is, when

$$
P \sim \frac{1}{2} \pi\left(1-v^{2}\right) \frac{D t \sigma_{C}^{2}}{E} .
$$

If $D$ is $10 \mathrm{~m}$, t $2 \mathrm{~m}, \sigma_{\mathrm{C}} 5 \mathrm{MN} \mathrm{m}^{-2}, \mathrm{E} 10 \mathrm{GN} \mathrm{m}^{-2}$, and $v$ 0.3 (appropriate values for ice), the corresponding value of $P$ is only $70 \mathrm{kN}$. This is an estimate of the ice force at which fracture starts; the corresponding contact breadth is only $0.1 \mathrm{~m}$, and so the ice has hardly come into contact with the structure. Continued movement of the ice towards the structure will generate a crushed contact zone (Fig.4(a)) within which the stress components are of the order of $\sigma_{c}$. This zone will extend progressively horizontally, as well as vertically inwards froll the upper and lower free surfaces towards the midplane of the ice cover, where triaxial constraint tends to suppress fracture. The distribution of normal stress oyy across the plane of syminetry is shown in Figure $4(b)$; this stress compponent will be compressive close to the contact and tensile further away. If the maximum tensile value of $\sigma_{y y}$ just outside the crushed region reaches the fracture stress in tension, a crack can initiate and propagate in the positive $x$-direction. Figure $4(b)$ shows such a crack extended to a length $c$. Its growth can be analysed through the methods of fracture mechanics, whose application to ice has been discussed by Goetze (unpublshed), Smith (1978), Goodman (1979), and others. The crack can be idealized as an edge crack in a semi-infinite plate, wedged open by opposed crack-opening forces F (Fig.4(b)) equal to the transverse compressive force in the crushed region close to the contact. The corresponding stress intensity factor is $2.590 \mathrm{~F} / \mathrm{t} \sqrt{\pi \mathrm{C}}$ ( $\mathrm{Sih} 1973$ ). $F$ siould be proportional to the ice force $P$ : therefore, we choose to take $F$ as $\alpha P$, where $\alpha$ is a proportionality constant. Once initiated, the crack will extend until the stress intensity factor for the crack tip falls to the fracture toughness $K_{I c}$, i.e. unti]

$$
K_{I c}=2.590 \mathrm{~F} / t \sqrt{\pi c},
$$

and so

$$
c=2.13\left[\frac{\alpha P}{t_{K} I C}\right]^{2} \text {. }
$$

Taking $\mathrm{K}_{\mathrm{I} g}$ as $115 \mathrm{kN} \mathrm{m}^{-3 / 2}$ (Goodman 1979), $\alpha$ as 0.5 , and $t$ as $\{\mathrm{m}$, saniple load values to propagate a crack are:

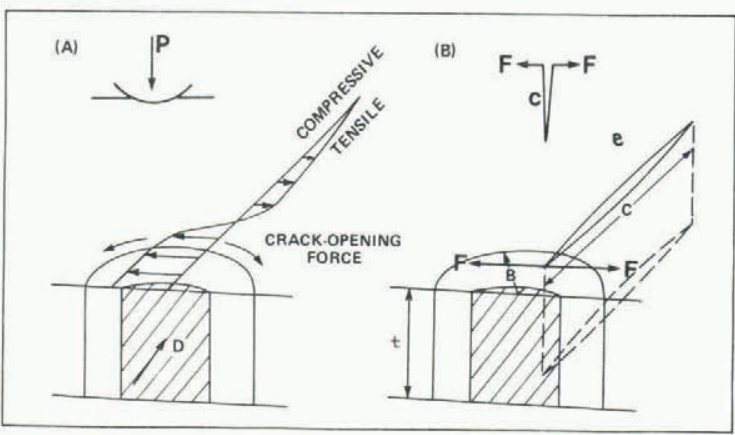

Fig.4. Distribution of stress in front of a cylindrical indenter $(A)$, and a single radial crack opened by a wedge opening force $F(B)$. 


$\begin{array}{rr}\text { Load } & \text { Crack length } \\ 100 \mathrm{kN} & 0.1 \mathrm{~m} \\ 1 \mathrm{MN} & 10.0 \mathrm{~m} \\ 10 \mathrm{MN} & 1000.0 \mathrm{~m}\end{array}$

The growth of the crack is stable, but it extends very rapidly as $P$ increases, and this result ought not to be sensitive to the details of the stress-strain relation, since the crack is advancing into the elastic region far from the contact, where stresses are low. The choice of $\alpha$ as 0.5 is comparable with the value found for axisymmetric indentation (Lawn and others 1980).

Stable growth of a radial crack at right angles to the edge of the ice cover does not itself lead to other kinds of fracture, but the process of initiation and growth of radial cracks can be repeated. In each of the right-angled sectors into which the crack divides the ice cover, there will again be a transverse tensile stress across planes that bisect the sectors, al though the loading on a sector is no longer symmetric. A second and a third crack can initiate in each sector, the sectors can split again, and so on.

Analogy with axisymmetric indentation suggests that the array of radial cracks would have crack lengths comparable to the length of a single radial crack, except at very high crack densities, where the lengths of individual cracks would diminish.

The ice cover has so far been treated as if it were stress-free. It is quite possible for a stress to exist in the $y$-direction in the plate; if the stress is tensile, the growth of the crack can become unstable. Consider again the case of the single crack shown in Figure $4(\mathrm{~b})$, if a remote stress $\sigma_{s}$ exists in the ice, the stress intensity factor becomes

$$
K_{I}=2.590 \alpha P / t \sqrt{\pi c}+1.12 \sigma_{S} \sqrt{(\pi c)}
$$

If $K_{I}$ reaches the critical value $K_{I c}$, the crack will grow to a length which is smaller than the roots of

$$
0=\left(1.12 \sigma_{S} \sqrt{\pi}\right) c \sqrt{\pi}-K_{I c} \sqrt{c}+1.461 \alpha P / t .
$$

The crack becomes unstable when

$$
P=0.086 \mathrm{~K}_{\mathrm{I}}^{2} \mathrm{t} / \alpha_{\mathrm{S}}
$$

and

$$
c=0.071\left(K_{I C} / \sigma_{S}\right)^{2} .
$$

When $P$ and $c$ reach these values the ice will split across. If the tensile transverse stress is $0.01 \mathrm{MN} \mathrm{n}^{-2}$ (less than $1 \%$ of the stress at which tensile fracture occurs, and of the same order as the stresses induced in floating ice by waves (Goodman and others 1980)), $\mathrm{K}_{\mathrm{Ic}}$ is $115 \mathrm{kN} \mathrm{m}^{-3 / 2}, \alpha 0.5$, and $t 2 \mathrm{~m}$, the critical force at which the sheet splits is $0.5 \mathrm{IN}$ and the critical length is only 10 $\mathrm{m}$. Thus very small tensile stresses will substantially reduce the force needed to fracture an ice cover. Transverse compressive stresses will, on the other hand, exert a stabilizing effect.

The estimates of $P$ and $c$ are not numerically precise, because of the need to estimate $\alpha$, and ought to be checked by comparison with experiments on wellcharacterized brittle materials not subject to creep, following the parallel work on normal indentation by Lawn and others (1980). However the observations do confirm the observation that because ice has such a low fracture toughness, small forces can make cracks propagate a long way.

\section{IMPLICATIONS FOR FORCE CALCULATIONS ON REAL STRUCTIJRES}

The analysis above calculates the wedge opening force $P$ required to propagate a crack radially away from the structure. Because the ice must still clear around the structure, this load will not necessarily be the maximum load the structure will see. However it is instructive to compare the order of magnitude of $P$, with the total loads acting on a structure estimated from al ternative models.

Consider first a plasticity model (Ralston 1978) for a structure which has a diameter of $100 \mathrm{~m}$ and ice cover which is $2 \mathrm{~m}$ thick. If the ice is idealizer as a perfect plastic von Mises material with yield strength $5 \mathrm{MN} \mathrm{m}^{-2}$ (corresponding to an ice velocity of $\left.0.02 \mathrm{~m} \mathrm{~s}^{-1}\right)$, and the indentation factor is taken as 1 , Ralston's model would estimate the force on the structure to be $1000 \mathrm{MN}$ (100 000 tonnes). This is 14000 times the estimated force at which fracture begins and 100 times the force that can propagate a crack to a distance of $1 \mathrm{~km}$. If the yield strength is $0.5 \mathrm{MN} \mathrm{m}^{-2}$, the force calculated from a plasticity model would be 100 Mil. More sophisticated plasticity models take account of anisotropy, and of yield functions that include the effect of the first stress invariant, but give results of the same order of magnitude.

Radial cracking may not itself limit the maximum ice force, but the gross changes of geometry that it causes must be taken into account in the load calculation. The presence of radial cracks may for instance allow flexural buckling to occur at a lower load than would occur in an uncracked sheet (Kerr 1978). Circunferential cracking will follow radial cracking, and it may limit the load because triangular fragments will break away and ride up over the uncracked sheet.

\section{CONCLUSIONS}

It is no more likely that there should be a universal ice-force formula than that there should be a universal formula for the force on a body in a moving fluid, and in the present state of knowledge, it would be unwise to expect too much.

Calculations based on elementary fracture mechanics confirm observations that suggest that many modes of ice deformation are governed by fracture. The corresponding forces are very sma11 by comparison with forces calculated from plasticity or creep nodels, and this suggests that for certain geometries and ranges of movement rates fracture phenomena may determine design loads for offshore structures in ice.

\section{ACKNOWLEDGEMENTS}

The authors wish to thank the British Petroleum Company PLC for permission to publish this paper, and acknowledge support under a research contract with the University of Manchester Institute of Science and Technology, Manchester, England.

\section{RFEFERENCES}

Croasdale K R 1975 Ice forces on marine structures. In IAHR. Intermational Association for Hydraulic Research. Third international symposium on ice problems, Hanover, New Hampshire, 1975. Proceedings: 315-337

Croasdale K R, Marcellus R W 1982 I ce forces on large marine structures. In IAHR. Intermational Association for Hydraulic Research. International symposium on ice, Québec, Canada, 1981. Proceedings Vol.1: 755-766

Croasdale K R, Morgenstern N R, Nuttall J B 1977 Indentation tests to investigate ice pressures on vertical piers. Joumal of Glaciology 19(81): 301-312

Frederking R, Gold L W 1972 Ice forces on an isolated circular pile. In POAC 71: the first International Conference on Port and Ocean Engineering under Arctic Conditions, Trondheim, Norway, 1971. Proceedings Vol 1: 73-92

Goetze C F Unpublished. A study of brittle fracture as applied to ice. CRREL Technical Note [1965] 
Goodman D J 1979 Critical stress intensity factor ( $\mathrm{K}_{\mathrm{IC}}$ ) measurements at high loading rates for polycrystalline ice. In Tryde $P$ (ed) Intemational Union of Theoretical and Applied Mechanics. Physics and mechanics of ice. Symposium Copenhagen ... 1979 ... Berlin etc, Springer-Verlag: 129-146

Goodman D J 1980 Fracture toughness ( $\mathrm{K}_{\mathrm{Ic}}$ ) measurements for polycrystalline ice at high strain rates. In Fukuda A (ed) Köri no butsuri kagaku ni kan-suru kenkyu [Research on the physics and chemistry of ice]. Monbusho Kagaku Kenkyu-hi Hojokin [1978-79] Sogo Kenkyū (A). Kenkyū Seika Hokokusho (Hokkaido): 85-94

Goodman D J. Wadhans P, Squire V A 1980 The flexural response of a tabular ice island to ocean swe11. Annals of Glaciology 1: 23-27

Kerr A D 1978 On the determination of horizontal forces a floating ice plate exerts on a structure. CRREL Report 78-15

Kry P R 1982 Scale effects in continuous crushing of ice. In IAHR. Intermational Association for Hydraulic Research. International symposium on ice, Québec, Canada, 1981. Proceedings Vol 2: 565-580

Lawn B R, Evans A G', Marshall D B 1980 Elastic/ plastic damage in ceramics: the median/radial crack system. American Ceramics Society Bulletin 63(9-10): 574-581

Goodman D J 1980 Fracture toughness (KIc) measurements for polycrystalline ice at high strain rates. In Fukuda A (ed) Kōri no butsuri kagaku ni kan-suru kenkyü [Research on the physics and chemistry of ice]. Monbusho Kagaku_Kenkyu-hi_Hojokin [1978-79] Sogo Kenkyu (A). Kenkyu Seika Hokokusho (Hokkaido): $85-94$

Michel B, Toussaint N 1977 Mechanisms and theory of indentation of ice plates. Joumal of Glaciology 19(81): 285-300

Ralston T D 1978 An analysis of ice sheet indentation. In IAHR. International Association for Hydraulic Research. Symposium on ice problems, Luteå, Sweden, 1978. Proceedings Part 1: 13-31

Sarpkaya T, Isaacson M de St Q 1981 Mechanics of wave forces on offshore structures. New York, etc, Van Nostrand Reinhold Co.

Schwarz J, Hirayama K 1973 Experimental study of ice forces on piles and the corresponding ice deformation. Iowa City, IA, University of I owa. Iowa Institute of Hydraulic Research. Report

Sih G C M 1973 Handbook of stress intensity factors for researchers and engineers. Bethlehem, PA, Lehigh University. Institute of Fracture and Solid Mechanics

Simith R A 1978 Iceberg cleaving and fracture mechanics: a preliminary survey. In Husseiny A A (ed) Iceberg utilization. Proceedings of the first Intermational Conference, Ames, Iowa, 1977. New York, Pergamon Press: 176-190

Zabilansky L J, Nevel D E, Haynes F D 1975 Ice forces on model structures. Canadian Joumal of Civil Engineering 2(4): 400-417 